\title{
0 processo de compras e o desafio da etapa do planejamento: 0 caso da Universidade Federal Rural de Pernambuco
}

\section{The purchases process and challenge in the planning stage: the case of the Universidade Federal Rural de Pernambuco}

\author{
Aldo Rios Soares Mestre, Programa de Pós-Graduação em Gestão Pública para o Desenvolvimento do \\ Nordeste (MGP), Brasil - aldoriso@gmail.com \\ Jorge da Silva Correia-Neto Doutor, Universidade Federal Rural de Pernambuco (UFRPE), Brasil - \\ jorgecorreianeto@gmail.com \\ Emanuela Sousa Ribeiro Doutora, Universidade Federal de Pernambuco (UFPE), Brasil - \\ emanuelasousaribeiro@yahoo.com.br \\ Luciano Magalhães Ferreira Mestre, Universidade Federal Rural de Pernambuco (UFRPE), Brasil - \\ adm.luciano@gmail.com
}

\section{RESUMO}

O objeto deste estudo é investigar a etapa do planejamento do processo de compras da Universidade Federal Rural de Pernambuco. Analisa o processo de compras para compreender os motivos de a universidade não planejar as suas compras e, como consequência, gerar compras fracionadas, sem um cronograma de execução factível. Mais especificamente, investiga as causas dos gargalos que ocorrem durante a fase de planejamento, prioriza as causas principais relativas ao impacto que a etapa do planejamento exerce sobre o problema e propõe ações para saná-las. Devido a sua natureza participativa e prática, o método da pesquisa-ação mostrouse adequado para o desenvolvimento do estudo que requereu participação dos servidores da citada universidade. Mediante uso do diagrama de Ishikawa, cinco causas principais foram identificadas e mediante uso da técnica $5 \mathrm{~W} 2 \mathrm{H}$ foram sugeridas ações de melhoria para cada uma das causas encontradas.

Palavras-chave: Compras públicas. Planejamento de compras. Pesquisa-ação. Ishikawa. Universidade Federal Rural de Pernambuco.

\section{ABSTRACT}

The object of this study is the planning stage of the purchasing process of the Federal Rural University of Pernambuco. It analyzes the purchasing process to understand the reasons why the university does not plan its purchases and, as a consequence, generate fractional purchases, without a feasible execution schedule. More specifically, it investigates the causes of the bottlenecks that occur during the planning phase, and it prioritizes the main causes related to the impact that the planning stage exerts on the problem. It also proposes actions to solve such problems. Due to its participatory and practical nature, the action-research method was adequate for the development of the study that required the participation of the servers. By using the Ishikawa diagram, five main causes were identified and through the use of the $5 \mathrm{~W} 2 \mathrm{H}$ technique actions were suggested aiming at the improvement for each of the causes found.

Keywords: Public Purchases. Purchasing Planning. Action Research. Ishikawa. Rural Federal University of Pernambuco.

Recebido em 15/04/2019. Aprovado em 23/04/2019. Avaliado pelo sistema double blind peer review. Publicado conforme normas da APA. http://dx.doi.org/10.22279/navus.2019.v9n4.p246-273.958 


\section{INTRODUÇÃO}

A Lei n. 8.666/1993, que regulamentou o artigo 37, inciso XXI da Constituição Federal, delegou considerável autoridade às universidades para tomar decisões de compra. Seguir a referida lei é cumprir procedimentos que garantem que o processo ocorra conforme a normas para licitações e contratos da administração pública pertinentes a obras, serviços, compras, alienações e locações no âmbito dos Poderes da União, dos Estados, do Distrito Federal e dos Municípios.

Hall, Moura, Macêdo e Cunha (2014) destacam que as universidades são entidades que gozam de autonomia perante a Constituição Federal, em que suas escolhas e modelos administrativos refletem sua estrutura interna de conselhos e câmaras de discussão e decisão. Porém, quando se refere à Lei n. 8.666/1993, as universidades devem cumprir determinados direcionamentos comuns a todas as entidades públicas, mesmo que muitas vezes ela se caracterize como fator de endurecimento, entraves e burocratização dos processos de compras no setor público.

Ao longo dos tempos, governos criam normas para aumentar a eficiência de suas aquisições. $E$ as universidades, por sua vez, capacitam seus servidores, elaboram manuais orientativos e redesenham processos - a fim de tornar a aquisição de produtos ou a prestação de serviço menos onerosa, mais eficiente e comprar com melhor qualidade (A. R. Motta, 2010; Tridapalli, Fernandes, \& Machado, 2011; Andrade, 2012).

Todavia, ao se conceber o termo licitação na abrangência de "[...] qualquer procedimento que tenha finalidade de selecionar seja através de preço mais conveniente, seja através da qualidade mais adequada, ou de ambos, a melhor oferta de bens ou serviços oferecida ao Estado por particulares" (Bezerra, 2008, p. 12), o que se pretende mesmo é estabelecer isonomia e transparência no processo de compras. Isso, por si só, já é um empecilho para garantir eficiência e eficácia no processo.

Quando o objetivo é isonomia e transparência, o processo tem mais importância do que o resultado. A obrigação de servidores de um órgão administrativo público de prestar contas às instâncias controladoras ou a seus representados diz respeito ao processo, mais do que aos resultados. Não se estranha, assim, a associação entre burocracia e abundância de papéis, rigorosidade de normas, excesso de formalismo e ineficiência. O Tribunal de Contas da União (TCU), por exemplo, fiscaliza se os procedimentos foram corretamente seguidos, mas não leva em conta o tempo de trâmite do processo, ou se as compras chegaram no prazo requerido pelo solicitante.

Behn (1995) já disse que quando não se consegue motivar as pessoas para que atinjam os resultados organizacionais, ou seja, quando não se consegue motivá-los para fazer a coisa certa, o resultado é tentar impedi-los de fazer a errada, o que se dá via proliferação de normas e procedimentos, engessando a organização.

Portanto, o bom desempenho do processo de compras parece não depender de controles restritos e centralizados e, à primeira vista, parece que a simples eliminação das restrições não é suficiente para garantir o bom desempenho e a correção no uso dos recursos públicos. A ênfase no estudo de Weber a respeito da burocracia é dada por muitos autores nas suas virtudes organizacionais, e, por outros, no oposto: como defender-se ante este avanço implacável da burocracia. A falta de burocracia pode estar mais próxima do diagnóstico correto, observa Evans (1993). Ou seja, a burocracia, muitas vezes, tem merecido menos atenção do que deveria.

Evans (1993) está se referindo ao contraste entre o caráter pré-burocrático, patrimonialista do Estado predatório e o caráter mais estreitamente weberiano dos Estados desenvolvimentistas. Essa comparação, segundo esse autor, deveria provocar dúvidas naqueles que atribuem à ineficácia do serviço público a sua natureza burocrática. Por isso, a avaliação de Evans (1993) pode ainda ser atual, pois no Brasil, ainda é comum a existência de fortes características clientelistas e patrimonialistas no Estado até hoje.

Weber (1994) indicou ser objetivo da burocracia alcançar os fins do Estado, ou seja, a efetividade. É claro que atingir os fins esperados a qualquer preço levará, fatalmente, à ineficiência. Contudo, privilegiar os meios em detrimento dos fins esperados, certamente, também conduzirá à ineficiência. A questão é que os gestores públicos precisam administrar o erário público de maneira responsável e transparente de forma a conter os excessos nos gastos públicos, pois não se deve gerar despesa indiscriminadamente, principalmente, sem cobertura contratual e legal, ainda que o objetivo seja justificável. 
A questão que se coloca é que, no Brasil, o processo de compras parece precisar de ajustes em muitos órgãos, pelo menos é o que se lê em muitos estudos (A. R. Motta, 2010; Carvalho, 2012; Andrade, 2012; Branco, Brodbeck, \& Torres, 2013; Ferreira, 2015; Oliveira, 2015). Além disso, atualmente, as esferas governamentais estão diante de uma perspectiva crescente de déficits orçamentários, contingenciamento de recursos, e ajuste fiscal e, consequentemente, a necessidade e o desafio do controle do gasto (Raposo, Freitas, Silva, Fernandes, \& Silva, 2016). Por outro lado, a sociedade está exigindo mais transparência e equidade nos contratos públicos.

Dado esse contexto ora apresentado, o objeto deste estudo é a etapa do planejamento do processo de compras da Universidade Federal Rural de Pernambuco (UFRPE). O planejamento de compras refere-se à identificação das necessidades de bens e serviços que precisam ser adquiridos dentro do período vigente e a elaboração de um plano para supri-las, de acordo com as diretrizes de gestão da UFRPE e as limitações orçamentárias.

Como em outras organizações públicas, a UFRPE carece de um melhor planejamento das compras. Tal planejamento requer conhecimento da legislação vigente e procedimentos formalizados da demanda, mas principalmente programação antecipada dos produtos e serviços necessários para as operações de toda a universidade. Neste sentido, os maiores problemas que ocorrem no processo de compras na UFRPE se originam na fase do planejamento, no início do processo, e duas questões merecem atenção: compras que não são programadas e compras não compartilhadas e, portanto, fracionadas.

No primeiro caso, se a compra não é efetivada o recurso é realocado dentro da UFRPE porque o processo de compras não foi concluído. Um processo de compras pode gerar licitação deserta (não aparece fornecedor), ou situações nas quais o fornecedor pode oferecer um produto similar que não estava descrito no processo e para isso é preciso reavaliar a descrição, entre outras ocorrências. Devido ao curto período de tempo para realizar todo o processo, nesses casos os recursos são realocados para outras finalidades.

No segundo caso, as demandas de produtos iguais, similares ou com mesmas características de finalidades podem e deveriam ser planejadas e compiladas em uma única compra compartilhada em um único procedimento licitatório mais eficiente e econômico, mas isso nem sempre ocorre na organização estudada, por isso, com base na problemática exposta, a seguinte pergunta de pesquisa foi explorada ao longo deste estudo: quais os motivos de a UFRPE nem sempre planejar as suas compras e, como consequência, gerar compras fracionadas, sem um cronograma de execução factível?

O processo de compras nasce no demandante (que pode ser um docente ou um servidor técnicoadministrativo), que necessita suprir alguma necessidade. Atualmente, cada departamento planeja isoladamente suas compras e faz solicitações à Pró-Reitoria de Administração (PROAD) que, por sua vez, remete as solicitações ao Departamento de Compras e Licitações. A equipe de Compras e Licitações realiza a pesquisa de preços, elabora o mapa de preços, o termo de referência e as minutas de edital e de contrato (se for o caso), enfim, todos os procedimentos para formalização do processo de compra ou contratação de um serviço. Depois disso, o processo retorna à PROAD, é encaminhado para análise da Procuradoria Jurídica e volta para a PROAD, que autoriza a compra e remete à Diretoria de Compras e Licitações (DCL).

Historicamente, o Governo Federal libera a maior parte dos recursos no final de ano, e isso se reflete na realização das licitações, as quais, na sua maior parte, ocorrem no citado período. O fato de não saber ao certo de quanto e quando será de fato a liberação do orçamento, haja vista que podem ocorrer cortes orçamentários, somado à falta de planejamento, utilizando especialmente o sistema de registro de preços, os processos podem não ser finalizados e a UFRPE pode ter que redirecionar os recursos ou utilizá-los sem atendimento às necessidades de maior relevância.

Porém, com o processo logrando êxito, com a liberação do orçamento (mesmo atrasado), há a realização da compra. Com homologação pela autoridade competente, é emitida a nota de empenho e, posteriormente, ocorre o recebimento do objeto. E quem já participou sabe que essa rotina nem sempre é assim linear, pois havendo erros, falhas ou ausência de algum documento, o processo para, ou fica indo e voltando sem atender devidamente ao solicitante no prazo desejado.

Justifica-se, mais uma vez, a importância de fazer o pedido de compras planejado, para evitar devolver ou realocar recursos destinados para esse fim. O planejamento, considerando sempre o estoque e a previsão do consumo no período, visa prover a UFRPE dos itens necessários às atividades normais da universidade. 
O planejamento das compras deve garantir a continuidade das operações da UFRPE, por isso deve ser entendido como um conjunto de medidas preventivas, no caso de qualquer atraso na liberação do orçamento. Essas medidas, muito além da simples adoção de um plano de compras, devem garantir que a universidade opere em bases contínuas. Para tanto, esse plano deve assegurar que todos os processos de trabalho tenham suas necessidades de compras identificados, e seus estoques monitorados e controlados.

Contudo, o Departamento de Compras e Licitações não consegue realizar um planejamento geral, porque não tem acesso, no período adequado, às necessidades de toda a universidade. Assim, os objetivos, relacionados ao conteúdo intrínseco do tema-problema e aos eventos que nele são observados são: analisar o processo de compras da UFRPE para compreender os motivos de a universidade não planejar as suas compras e, como consequência, frequentemente gerar compras fracionadas, sem um cronograma de execução factível. Mais especificamente, investigar as causas dos gargalos que ocorrem durante a fase de planejamento das compras, priorizar as causas principais relativas ao impacto que a etapa do planejamento exerce sobre o problema e propor ações para saná-las.

Assim, este estudo aponta medidas de planejamento das compras na UFRPE, pois acredita-se que tais medidas, se bem identificadas e implementadas, possibilitam economia de escala, evitam fracionamento nas compras, racionalizam os procedimentos internos e melhoram a gestão dos recursos públicos, evitando desperdício de produtos e serviços públicos.

Embora tais discursos não possam ser aqui estendidos, do ponto de vista acadêmico, este estudo estimula o debate sobre até que ponto a burocracia se torna um entrave na gestão de um processo, e até onde ela se faz necessária para o melhor gerenciamento da cadeia de processos de uma organização.

Debater sobre as características da burocracia inclui um debate sobre todas as ações desenvolvidas no âmbito do planejamento de compras executados pelos seus mais distintos agentes. Compreender os fundamentos sobre os quais tais ações de planejamento se assentam é também adentrar nas várias faces da racionalidade. Como já assinalou F. C. P. Motta (1979), questões como essas nos ajudam a perceber as diferenças entre o "tipo ideal" de burocracia e a realidade.

Na próxima seção discutir-se-á sobre as bases teórico-conceituais que fundamentaram o estudo.

\section{BUROCRACIA E O PROCESSO DE COMPRAS PÚBLICAS}

A burocracia tem sido estudada em várias as áreas do conhecimento, contudo, a grande contribuição sobre o tema foi realizada por Weber (1982), quando a administração pública substituía as formas patrimonialistas de gestão. A burocracia apresentava-se como reação ao nepotismo e ganhava importância em função da necessidade de maior previsibilidade e precisão no tratamento das questões organizacionais.

Portanto, é importante compreender e levar em conta o contexto histórico em que a teoria da burocracia foi escrita. Como evidenciam Faria e Meneghetti (2011), Weber analisa o processo de racionalização da sociedade na passagem da Idade Média para a Idade Moderna. "O desencantamento do mundo, baseado no cálculo utilitário de consequências, substitui a mediação das relações sociais que antes estavam baseadas na tradição e no carisma." (Faria \& Meneghetti, 2011, p. 426). Ou seja, uma racionalidade instrumental-legal se institui e modifica as relações na sociedade, fazendo com que a burocracia moderna se consolide como razão materializada desse processo histórico.

Faria e Meneghetti (2011) destacam ainda que a teoria da burocracia de Weber ocorre em um período de formação econômico-social do capitalismo. As características racionais da burocracia moderna são próprias e se instauram em um modo de produção específico e, segundo Weber (1982, p. 257) "Um processo correspondente ocorre nas organizações públicas".

No processo de compras, todas as comunicações, atos, processos e procedimentos devem ser realizados por escrito, em documentos apropriados, de modo a garantir comprovações, principalmente nos procedimentos licitatórios e no sistema de registro de preços. As normas, regulamentos, processos e procedimentos são elaborados em documentos e aprovados por servidores com autoridade formal, conforme as relações hierárquicas estabelecidas no organograma.

Weber (1982) observava que a burocracia pressupunha a divisão do trabalho de forma sistemática com vistas a satisfazer a uma racionalidade a qual estaria em conformidade com o objetivo almejado. Essa 
divisão sistemática do trabalho seria realizada levando em consideração o aspecto funcional da burocracia, com estabelecimento de normas escritas, de um poder hierárquico delimitado por meio de organograma, além do estabelecimento das funções, áreas de competência e de responsabilidade de cada cargo e sob a supervisão de um superior.

Porém, com todas essas características da burocracia, parece que o tipo de racionalidade que está subjacente no planejamento de compras não alcança as expectativas de comportamento das pessoas, nem tampouco seus fins próprios racionalmente perseguidos.

Se considerarmos as análises de Guerreiro Ramos (1989), a razão instrumental é o próprio substrato das burocracias organizadas e, no domínio das organizações, o compromisso com a racionalidade funcional leva a um falso pragmatismo - a busca desenfreada pelas soluções dos problemas organizacionais acaba por ocultar a essência dos mesmos.

Na burocracia, as considerações de F. C. P. Motta (1979) destacam a relevância da disciplina e essa só se realiza se os padrões estabelecidos forem sustentados por sentimentos que garantam a dedicação dos funcionários aos deveres burocráticos. Em última instância, portanto, a eficácia da burocracia depende da inculcação de atitudes e sentimentos apropriados a seu funcionamento.

Ocorre, porém, que tais sentimentos inculcados tendem a se intensificar mais do que o necessário, pelo apego excessivo às exigências dos procedimentos burocráticos. Tal inculcação, estimulada pelo formalismo dos pequenos procedimentos, leva ainda à transferência da identificação com os meios, representados pela conduta exigida pelas normas (F. C. P. Motta, 1979).

No processo de compras da UFRPE o volume excessivo de papel, em decorrência do formalismo exacerbado, gera ineficiência, justamente o contrário do que a burocracia propõe. Consequentemente, tais atitudes repercutem na sociedade a imagem de que o serviço público não evolui e que os funcionários são morosos, folgados e improdutivos.

A próxima seção apresenta o percurso metodológico seguido para atingir o objetivo geral traçado.

\section{PROCEDIMENTOS METODOLÓGICOS}

Volpato (2013) assinala que a ciência é uma estratégia de gerar conhecimento e interpretar o mundo. Segundo esse autor, o produto desse conhecimento pode ser aplicado imediatamente ou pode não apresentar uma aplicação prática imediata. Portanto, a diferença entre o conhecimento básico e o aplicado não está na forma de construção de uma pesquisa, mas na sua correspondência social, isto é, se tem uma utilidade imediata ou não. Assim, o conhecimento serve tanto para resolver problemas práticos imediatos (ciência aplicada) ou não (ciência básica).

Nesta perspectiva, fundamentado em Volpato (2013), podemos assumir que esta é uma pesquisa aplicada, visto que há uma intencionalidade explícita expressando um caráter político do problema ao qual se pretende solucionar.

Por isso, a pesquisa-ação é adequada para este estudo, pois esse tipo de pesquisa oscila entre agir no campo da prática e investigar a respeito dela. É um método que se aplica a estudos como o que aqui se apresenta, em que os servidores públicos de uma universidade buscam efetuar transformações em suas próprias práticas. Trata-se, antes de tudo, de fazer uma reflexão sobre a ação (Tripp, 2005).

A pesquisa-ação é um tipo de pesquisa social com base empírica que, segundo Thiollent (2011), os pesquisadores e os participantes representativos do problema estão envolvidos de modo participativo. Para garantir $\mathrm{o}$ atendimento aos requisitos legais que orientam as compras públicas foram consultados os seguintes documentos: a) Lei n. 8.666/1993 - dispõe sobre normas para licitações e contratos da Administração Pública e dá outras providências; b) Manual de Compras da UFRPE versão 2013 - define parâmetros para solicitação de compras de materiais e contratação de serviços.

A coleta de dados contou com a realização de duas reuniões de trabalho, com a presença de servidores (docentes e técnicos-administrativo) envolvidos no processo de compras, todos convidados para analisar o processo de compras, especificamente a fase do planejamento. 
A primeira reunião de trabalho foi realizada no dia 22 de maio de 2018, com 19 (dezenove) participantes, e a segunda foi realizada no dia 5 de junho de 2018, com 11 (onze) dos participantes da primeira reunião, mais outros 02 (dois) que se integraram ao processo.

No primeiro encontro foram apresentados a justificativa, os objetivos, o problema e a metodologia a ser aplicada na pesquisa. Foram também apresentados o diagrama de Ishikawa, a Matriz GUT e o Plano de Ação 5W2H como as principais ferramentas a serem utilizadas na melhoria do processo em estudo.

Ishikawa criou o Diagrama de Causa e Efeito, também conhecido como Espinha de Peixe ou Diagrama de Ishikawa, que viabiliza classificar em categorias de causas a um determinado problema (Mello, Silva, Tuttioni, \& Souza, 2002). Essas categorias permitem classificar as causas potenciais e, assim, identificar mais claramente as oportunidades de melhoria.

A Matriz de Gravidade, Urgência e Tendência (GUT) é uma técnica usada para priorizar as causas dos problemas, levando em consideração: a) gravidade - diz respeito ao impacto do problema sobre operações ou pessoas da organização; b) urgência - se refere ao tempo necessário para resolver o problema; c) tendência relativo ao potencial de piora do problema (Kepner \& Tregoe, 1981). Seguindo a concepção de Kepner e Tregoe (1981), para cada dimensão são atribuídas notas, com base na seguinte escala crescente: nota 5 para os maiores valores e 1 para os menores. As principais causas identificadas, geralmente as três ou cinco primeiras, devem receber atenção do gestor, preferencialmente mediante um plano de ação para corrigir o problema.

A sigla 5W2H é formada pelas iniciais, em inglês, as quais, segundo Meira (2003), se caracterizam em sete questões que, quando bem estabelecidas, eliminam as dúvidas que possam aparecer ao longo de um processo ou de uma atividade. São elas: what (o que será feito); why (porque será feito); where (onde será feito); when (quando será feito); who (por quem será feito); how (como será feito); how much (quanto vai custar). O objetivo do plano é a eliminação das causas principais que geraram um determinado problema.

Depois da apresentação dessas ferramentas, as pessoas foram dispostas em cinco grupos, para fazerem o levantamento das causas, obedecendo o disposto no diagrama apresentado. Em seguida, as causas foram agrupadas em uma grande planilha, perfazendo um total de 20 (vinte) pessoas.

Em seguida, os participantes, individualmente, aplicaram a matriz para priorizar as causas. Só foram finalizadas 13 (treze) análises, pois alguns fizeram em dupla e outros pediram para entregar no dia seguinte, de modo a organizarem melhor as informações. Posteriormente, no segundo encontro, as cinco causas principais foram priorizadas nos grupos formados no encontro anterior e a decisão das causas definitivas foram acordadas no grande grupo.

Ao final, cada grupo se responsabilizou pela elaboração de um plano de ação de uma das causas, cujo resultado foi apresentado e aprovado pelos participantes.

\section{RESULTADOS}

O Quadro 1 apresenta resumidamente os resultados, focando nas causas do problema, nas propostas de melhorias e em uma descrição de cada uma delas. Alguns elementos dos resultados foram suprimidos sem que isso comprometa o conteúdo central da pesquisa.

\begin{tabular}{|l|l|l|}
\hline \multicolumn{1}{|c|}{ Causas do problema } & Propostas de melhoria & \multicolumn{1}{c|}{ Descrição } \\
\hline $\begin{array}{l}\text { Falta de controle da etapa } \\
\text { de planejamento do } \\
\text { processo de compras. }\end{array}$ & $\begin{array}{l}\text { Diagnóstico, revisão e e } \\
\text { mapeamento do processo } \\
\text { atual. }\end{array}$ & $\begin{array}{l}\text { A análise do processo de compras e o seu } \\
\text { mapeamento já está sendo realizada mediante } \\
\text { uso da metodologia Business Process } \\
\text { Management (BPM), mediante uso do software } \\
\text { Bizagi. }\end{array}$ \\
\hline $\begin{array}{l}\text { Solicitante da compra não } \\
\text { descreve os pedidos de } \\
\text { maneira precisa e e } \\
\text { completa. }\end{array}$ & $\begin{array}{l}\text { Criação de um catálogo de } \\
\text { produtos e serviços } \\
\text { descritivo e dinâmico, } \\
\text { específico por } \\
\text { departamento. }\end{array}$ & $\begin{array}{l}\text { Cada departamento forma um grupo para } \\
\text { elaboração do catálogo, com uma foto e } \\
\text { descrição do produto ou serviço. Facilita a } \\
\text { escolha e definição do produto ou serviço. }\end{array}$ \\
\hline
\end{tabular}




\begin{tabular}{|c|c|c|}
\hline $\begin{array}{l}\text { Não há um cronograma } \\
\text { das compras definido e } \\
\text { divulgado entre os } \\
\text { solicitantes. }\end{array}$ & $\begin{array}{l}\text { Elaboração e divulgação } \\
\text { do cronograma de } \\
\text { compras. }\end{array}$ & $\begin{array}{l}\text { As Diretorias terão o prazo determinado no } \\
\text { Cronograma de Compras para encaminhar suas } \\
\text { demandas. Como sugestão, indica-se o mês de } \\
\text { maio de cada ano. Com as informações } \\
\text { disponíveis, a Diretoria de Compras e Licitação } \\
\text { terá todo o } 2^{\circ} \text { semestre para agrupar as } \\
\text { demandas, fazer a pesquisa de mercado, } \\
\text { elaborar os documentos e realizar o } \\
\text { procedimento licitatório antes do final do ano } \\
\text { corrente. Evita que os recursos de compras sejam } \\
\text { realocados para outras finalidades porque as } \\
\text { compras não foram realizadas em tempo de } \\
\text { realizar todo o processo. }\end{array}$ \\
\hline $\begin{array}{l}\text { Falta de atualização, } \\
\text { divulgação e acesso aos } \\
\text { procedimentos de } \\
\text { compras. }\end{array}$ & $\begin{array}{l}\text { Atualização sistemática do } \\
\text { processo tão logo mude } \\
\text { alguma norma, assim } \\
\text { como divulgação e } \\
\text { treinamento } \\
\text { servidores sobre os } \\
\text { procedimentos. }\end{array}$ & $\begin{array}{l}\text { Necessidade de padronização das solicitações de } \\
\text { compras para que todos os servidores saibam } \\
\text { como proceder para realizar sua parte na } \\
\text { execução das compras. }\end{array}$ \\
\hline $\begin{array}{l}\text { Solicitante não planeja } \\
\text { adequadamente o volume } \\
\text { de compras para o } \\
\text { período, considerando o } \\
\text { estoque, e não concentra } \\
\text { os pedidos em um único } \\
\text { processo nos seus devidos } \\
\text { setores ou } \\
\text { departamentos. }\end{array}$ & $\begin{array}{l}\text { Estabelecer o } \\
\text { planejamento de compras } \\
\text { por departamento. }\end{array}$ & $\begin{array}{l}\text { Cada demandante realiza um levantamento } \\
\text { minucioso da demanda por setor e o seu } \\
\text { posterior agrupamento por tipo de material, } \\
\text { reunindo os itens em um processo único. } \\
\text { Atendendo aos prazos, o processo é enviado à } \\
\text { Diretoria de Compras e Licitações que, por sua } \\
\text { vez, realiza um único procedimento licitatório } \\
\text { com vistas a atender aquela determinada } \\
\text { demanda, por exemplo: ração animal, vidrarias, } \\
\text { material de laboratório. Evita compras } \\
\text { fracionadas. }\end{array}$ \\
\hline
\end{tabular}

\section{Quadro 1. Resultados da pesquisa}

Fonte: Elaborado pelo Autor (2019).

Como se lê no Quadro 1, as causas do problema desta pesquisa se concentram na etapa do planejamento, mas se distribuem por todo o processo de compras. Mas, ficou evidenciado que não há uma fase de planejamento clara e orientada no processo de compras, nem tampouco o conhecimento de quando e como realizar uma solicitação por parte dos demandantes. O manual de compras existente não é suficiente para guiar os demandantes no planejamento de suas compras e nem é muito divulgado.

O objeto deste estudo reascendeu o debate em torno de um tema que parece continuar na esfera das discussões acadêmicas e que não quer desaparecer da realidade organizacional: a burocracia e as normas e regras inerentes à mesma.

Como se lê na maioria dos autores trazidos ao debate nesta pesquisa, uma das características mais fortes do modelo burocrático é que a organização é baseada no estabelecimento prévio de normas e regras administrativas, que devem ser cumpridas por todos os ocupantes dos cargos. A burocracia, embora normalmente seja mais notada por suas disfunções (lentidão, morosidade, ineficiência, excesso de papelada etc.) do que pela organização e benefícios que pode (ou poderia) gerar, foi idealizada visando criar mecanismos de organização das atividades administrativas que trouxessem soluções rápidas, eficientes e uniformes nas atividades desempenhas pelas organizações.

No entanto, o que este estudo constatou foi justamente a ausência de normas e procedimentos administrativos escritos relativos à etapa do planejamento de compras, características ideais da burocracia. Ou seja, devido à ausência de um documento oficial com a descrição e as instruções sobre o cronograma das compras, sobre a descrição dos itens de compras, sobre orientações para a concentração das compras, além de não haver um procedimento formal de comunicação com os solicitantes, os problemas se multiplicaram, 
entre eles compras não programadas e fracionadas, retrabalho e alocação dos recursos de compras para outras finalidades.

Ademais, a falta de padrão na sequência das atividades envolvidas, detalhando o fluxo do trabalho do processo de compras, ocasiona problemas concernentes à atualização dos procedimentos quando de mudanças da legislação e, também, impossibilita uma capacitação mais efetiva das pessoas envolvidas com as compras. Conclui-se que, quanto mais claramente um servidor sabe sobre os principais elementos das tarefas que executa e sobre o domínio em que atua, melhor habilidade ele tem de executar suas atividades. O desempenho de um processo de trabalho é caracterizado pela crescente consciência de suas interfaces funcionais, que são os pontos nos quais o trabalho que está sendo realizado é transferido de um setor para o seguinte. Nessas transferências é que normalmente ocorrem as negligências na relação entre cliente e fornecedor a e a perda de tempo.

\section{Considerações Finais}

Esse estudo investigou as causas da falta de planejamento das compras da UFRPE e apontou melhorias para solucionar o problema. Apesar da aplicação de procedimentos metodológicos simples, os mesmos alcançaram os objetivos e produziram resultados confiáveis. As reuniões de trabalho foram conduzidas pelos próprios pesquisadores, sendo um deles o diretor de compras da universidade. As reuniões foram realizadas em um ambiente dinâmico e com ampla cooperação e interesse por parte dos participantes. Foi privilegiada a participação dos servidores que integram o processo de compras em seus departamentos.

Sabe-se que a alta administração da UFRPE é a grande responsável pela validação e implementação das propostas sugeridas, mas esse é também o limite desta pesquisa: as melhorias foram sugeridas, porém não implementadas, embora muitas já estejam sendo realizadas, entre elas o redesenho do processo de compras.

Certamente, esta pesquisa-ação apontou soluções para cada causa do problema e, portanto, contribuiu para a melhoria do processo de compras. No entanto, ressalta-se que não se pretende julgar o significado, ou apurar a abrangência, a complexidade e a dinâmica que é o processo de compras de uma universidade pública federal, nem as relações que se estabelecem, entre outras mediações que entram em ação nesse processo. Isso não significa que atendidas essas premissas o processo funcione, pelo menos na etapa do planejamento. Existem outras variáveis que influenciam o processo de compras e que que não foram consideradas neste estudo, por exemplo, a disponibilidade das pessoas para realizarem a sua parte de trabalho no conjunto do processo.

Todavia, após a finalização da pesquisa, fica a proposta de execução dos resultados pela administração superior, pois entende-se que, devido à participação de técnicos administrativos e docentes, os quais se predispuseram a assumir responsabilidades em partes específicas do processo, há uma grande chance de melhorar o processo de compras como um todo, iniciando no planejamento.

Como sugestão para futuros trabalhos, indica-se o estudo em outras instituições de ensino superior de modo a levar a experiência adquirida neste trabalho e trazer mais evidências para melhorias das compras públicas no âmbito das universidades federais.

\section{REFERÊNCIAS}

Andrade, G. C. (2012). Gestão Estratégica de Suprimento em uma empresa do setor elétrico brasileiro. (Dissertação de Mestrado). Universidade Federal do Rio de Janeiro, Rio de Janeiro, RJ, Brasil.

Behn, R. D. (1995). The big questions of public management. Public Administration Review, 55(4), 313-324.

Bezerra, J. E. V. (2008). O pregão eletrônico como base para minimizar custos da gestão pública. (Monografia de Graduação). Centro Universitário de João Pessoa, PB, Brasil.

Branco, G. M., Brodbeck, A., \& Torres, I. S. (2013, maio). Estruturação do processo de compras em organizações governamentais: o caso de uma Instituição federal de Ensino Superior. VII Workshop de tecnologia da informação e comunicação das IFES, João Pessoa, PB, Brasil. 
Constituição da República Federativa do Brasil de 1988. Recuperado de http://www.planalto.gov.br/ccivil_03/Constituicao/Constituicao.htm

Evans, P. (1993). O Estado como problema e solução. Lua Nova: Revista de Cultura e Política. (28-29), 107-156.

Lei n. 8.666, de 21 de junho de 1993. Regulamenta o art. 37, inciso XXI, da Constituição Federal, institui normas para licitações e contratos da Administração Pública e dá outras providências. Recuperado de http://www.planalto.gov.br/ccivil_03/leis//8666cons.htm

Carvalho, R. G de. (2012). Compras privadas X compras públicas: o que os dados da aquisição de medicamentos nos dizem?(Dissertação de Mestrado). Fundação Getúlio Vargas, Rio de Janeiro, RJ, Brasil.

Faria, J. H., \& Meneghetti, F.K. (2011). Burocracia como organização, poder e controle. Revista de Administração de Empresas, 57(5), 424-439.

Ferreira, C. B. (2012). Gestão de compras públicas: desafios, dilemas e perspectivas na Universidade Federal de Viçosa. (Dissertação de Mestrado Profissional). Universidade Federal de Juiz de Fora, Juiz de Fora, MG, Brasil.

Guerreiro Ramos, A. (1989). A nova ciência das organizações: reconceituação da riqueza das nações. (2a ed.). Rio de Janeiro: Fundação Getúlio Vargas.

Hall, R. J., Moura, G. D., Macêdo, F. F. R. R., \& Cunha, P. R. (2014). Compras públicas sustentáveis: um estudo nas universidades federais brasileiras. Amazônia, Organizações e Sustentabilidade, 3(1), 27-44.

Kepner, C. H., \& Tregoe, B. B. (1981). O administrador racional. São Paulo: Atlas.

Meira, R. C. (2003). As ferramentas para a melhoria da qualidade. Porto Alegre: SEBRAE.

Mello, C. H. P., Silva, C. E. S. da., Tuttioni, J. B., \&Souza, L. G. M. (2002). ISO 9001:2000: sistema de gestão da qualidade para organizações de serviços. São Paulo: Atlas.

Motta, A. R. (2010). O combate ao desperdício no gasto público: uma reflexão baseada na comparação entre os sistemas de compra privado, público federal norte-americano e brasileiro. (Dissertação de Mestrado). Universidade Estadual de Campinas, Campinas, SP, Brasil.

Motta, F. C. P. (1979). Controle social nas organizações. Revista Administração de Empresas, 19(3), 11-25.

Oliveira, I. G. S. (2015). Análise de correspondência aplicada a preposições sobre a eficiência e eficácia do processo de compras públicas a partir da percepção de diferentes atores envolvidos. Revista Ciências Administrativas, 21(1), 131-162.

Raposo, M. H., Freitas, M. S., Silva, M. T., Fo., Fernandes, M.S.B., \& Silva, R.L. (2016). A importância do planejamento de compras para a gestão estratégica de suprimentos. Congresso CONSAD de Gestão Pública, 9.

Thiollent, M. (2011). Metodologia da Pesquisa-ação. (18a ed.). Porto Alegre: Editora Cortez.

Tridapalli, J. P., Fernandes, E., \& Machado, W. V. (2011). Gestão da cadeia de suprimento do setor público: uma alternativa para controle de gastos correntes no Brasil. Revista de Administração Pública, 45(2), 401433.

Tripp, D. (2005). Pesquisa-ação: uma introdução metodológica. Educação e Pesquisa, 31(3), 443-466.

Weber, M. (1994). Economia e sociedade: fundamentos da sociologia compreensiva. (3a ed., Vol. 1). Brasília: UnB. 
Weber, M. (1982). Ensaios de sociologia. (5a ed.). Rio de Janeiro: LTC Editora.

Volpato, G. (2013). Ciência: da filosofia à publicação. (6a ed.). São Paulo: Cultura Acadêmica. 